\title{
TREINAMENTO DE PROFESSORES DA ÁREA DE COMUNICAÇÃO E EXPRESSÃO, EM ATIVIDADES DE LEITURA: RELATO DE EXPERIÊNCIA
}

\author{
VILMA APARECIDA GIMENES DA CRUZ \\ TEREZINHA DE JESUS FOKAMA GONDO
}

\author{
CRUZ, V.A.G da; GONDO, T.J.G. Treinamento de Professores da Área de Comunicação e \\ Expressão em Atividades de Leitura: Relato de Experiência. Semina: Ci. Sociais/Humanas, \\ Londrina, v. 17, n. 3, p. 350-353, set. 1996.
}

\begin{abstract}
RESUMO: Relato do Projeto Treinamento de Professores da Área de Comunicação e Expressão de $5^{a}$ a $8^{a}$ séries do $1^{\circ} \mathrm{Grau}$, em Atividade de Leitura, realizado no período de 1992 a 1995 no Colégio Estadual Professor José Aloisio de Aragão, Londrina. Apresenta no geral as atividades desenvolvidas, a metodologia utilizada e a avaliação obtida no final do período experimental.
\end{abstract}

PALAVRAS-CHAVE: Treinamento de professores; Leitura; Atividades de Leitura.

\section{INTRODUÇÃO}

A leitura como instrumento capacita o indivíduo, o torna independente, assegura-lhe as condições de cidadão e the dá oportunidade para modificar seu contexto social. Em um país onde a leitura tem seu real valor, ele, com certeza, pode se desenvolver.

A leitura é processo constante. Desde criança o ser humano inicia o processo de "leitura" em um sentido mais amplo. Com o tempo, esta capacidade de ler vai se modificando de acordo com os estímulos que recebe, das mais diferentes formas.

$\mathrm{Na}$ fase escolar, a instituição educacional se encarrega da formação desta leitura, de modo a estabelecer um nível que proporcione ao indivíduo o acesso à cultura e à informação.

Neste contexto, pode-se observar que a leitura se inicia por um processo de decodificação de símbolos e, paulatinamente, através do currículo escolar, é trabalhada para que o aluno aprenda também a gostar deler.

Porém não é mistério para ninguém, que a escola não tem conseguido atingir esse objetivo plenamente e hoje sabe-se que esse papel não cabe somente a ela. Sabe-se também que a "descolarização" da leitura é um dos objetivos do PROLER (Programa de Leitura da Biblioteca Nacional), em função da atuação da escola em relação à formação dos leitores. Em muitos casos, o trabalho de formação do leitor tem o efeito contrário, devido a falta de preparo dessas instituições de ensino, a leitura passa a ser maltratada e os livros desprezados ficando, conseqüentemente, esta formação prejudicada.
Essa situação pode ser confirmada ao se observar - comportamento de leitura que os universitários apresentam, demonstrando que não há solidificação da mesma nos $1^{\circ}$ e $2^{\circ}$ graus.

Sendo assim, à escola e diretamente ao professor, é atribuída a função do ensino da leitura $e$, conseqüentemente, de estimular a leitura.Conforme prevê a lei 5692/1971, sobre a Reforma do Ensino, a escola deve buscar uma aprendizagem com base numa leitura de texto. Neste aspecto, observa-se pela literatura existente sobre o assunto, como também pela própria prática vigente, que a iniciação à leitura é atribuida principalmente aos professores da área de Comunicação e Expressão.

Neste contexto, deve-se interpretar a leitura em um sentido global.

A leitura não é mera decodificação, ela deve ser assimilada, incorporada, para provocar uma "resposta" ao que se lê. Isto é, através da leitura pode-se refazer muitos conceitos, mudar valores e até o comportamento. Através da leitura modifica-se fundamentalmente a relação que as pessoas têm com a realidade que as cerca.

Visando obter este nível de capacidade de ler, o indivíduo deve receber muitos estímulos, através de diferentes etapas e chegar ao "amadurecimento", isto é, à obtenção do "comportamento de ler" que é possivel através do gosto pela leitura.

Despertar este "gosto pela leitura" é papel fundamental da escola, apesar de que os novos conceitos não the atribuem exclusividade nessa função. A forma como ela vai atingir este objetivo é um fator 
preocupante para os profissionais envolvidos com a leitura.

Menciona-se esses profissionais porque são eles de diferentes áreas e todos têm uma participação direta sobre a questão, pois a leitura pode ser analisada e trabalhada ao nível pedagógico, psicológico, literário, lingüístico e também biblioteconômico.

A preocupação com a leitura como forma de lazer, ler pelo gosto de ler, sempre foi um ponto de interesse para os profissionais da área de Biblioteconomia, considerando-se que o bibliotecário tem também, na sociedade, um papel de educador, quando ele atua principalmente em instituições de ensino.

Desta forma, o desenvolvimento do gosto pela leitura pode ser obtido através de motivações geradas por meio de estratégias que tanto o bibliotecário quanto o professor em sala de aula poderiam adotar.

Isto confirma-se através de dados coletados em uma pesquisa realizada pelo Departamento de Biblioteconomia da Universidade Estadual de Londrina que procurou identificar o papel dos professores de $1^{\circ} \mathrm{e}$ $2^{\circ}$ graus como agentes de integração entre a informação e as atividades de ensino. Um dos aspectos investigados foi exatamente quais eram os procedimentos utilizados pelo professor para incentivar a leitura entre os alunos. Os resultados obtidos evidenciaram a ausência de um esforço planejado e voltado para o trabalho de leitura. Isto não quer dizer que não existiam professores interessados e atuando com a leitura, porém o percentual dos que atuavam era pequeno. Outro aspecto a ser considerado é o fato de que uma parcela significativa trabalhava a leitura de uma forma que podia ser considerada como não adequada, o que, na opinião de Bamberger (1977), toma-se prejudicial, pois a leitura não pode ser um processo mecânico, quando isso acontece ela perde sua função de estímulo mental e emocional e pode comprometer o raciocínio e a fantasia.

Neste sentido, muitas pesquisas são desenvolvidas e muitas ações a nível governamental ou até mesmo privadas, tais como o PROLER, Ciranda de Livros, Trabalhando com Jornais, da Folha de São Paulo, entre outras, são implantadas buscando a melhoria da condição de leitura do individuo.

Mudanças no sistema de ensino público também ocorreram causando melhoria de qualidade da aprendizagem.

Por outro lado, a experiência vivida através dos diferentes projetos de extensão desenvolvidos pelo Departamento de Biblioteconomia da UEL, que atuavam com a leitura a nivel de $1^{\circ}$ e $2^{\circ}$ graus, procurando incentivar o desenvolvimento da leitura entre os escolares, despertaram o interesse na realização de um projeto experimental que permitisse o desenvolvimento de atividades visando a melhoria do nível de leitura nas escolas. Sendo assim a proposta do referido projeto foi a de atuar junto aos professores da área de Comunicação e Expressão, de $5^{\mathrm{a}}$ a $8^{\mathrm{a}}$ séries do $1^{\mathrm{o}} \mathrm{grau}$.

\section{O PROJETO}

Iniciado em 1992, foi desenvolvido no Colégio Estadual professor José Aloísio Aragão, com uma professora de 2 turmas de $7^{\text {a }}$ série que foram acompanhadas, em 1993, na $8^{\mathrm{a}}$ série. Justifica-se o fato de não ter sido iniciado com a $5^{\mathrm{a}}$ série, em virtude de, na época, ter ocorrido falta e troca de professores da disciplina.

Em 1994, o trabalho foi desenvolvido com a protessora de 2 turmas da 5 a série que se estendeu com as mesmas turmas na 6ª série, em 1995.

Após esse período, em que foi possivel abranger turmas de $5^{\mathrm{a}}$ a $8^{\mathrm{a}}$ séries, o projeto foi encerrado visando uma avaliação global.

\section{ATIVIDADES}

As atividades de leitura propostas no desenvolvimento do projeto foram planejadas de acordo com o perfil de cada série abrangida. Procurou-se também diversificá-las, considerando que a leitura implica em conhecimento de textos de diversas modalidades, de busca de informação, entretenimento e lazer. A proposta buscou também ampliar o conhecimento dos alunos a respeito da existência de editores e livrarias, como também da própria biblioteca.

O planejamento das atividades era realizado com a participação da professora em treinamento, o que permitia uma melhor adequação das atividades pois ela fomecia dados sobre os alunos como também em alguns momentos adequava a atividade ao seu programa curricular.

Para o alcance dos objetivos acadêmicos, o aluno de Biblioteconomia participante do projeto, atuava em todas as fases, desde o planejamento à execução e avaliação das atividades.

O planejamento de cada atividade abrangia a definição dos objetivos e estabelecimento do roteiro de desenvolvimento que era entregue ao professor, e este, juntamente com o estagiário, executava a proposta. Após a realização de cada atividade era feita uma avaliação pela equipe do projeto e submetida e discutida com o professor.

Dependendo da modalidade da atividade ela poderia ou não obter um produto final, como por exemplo, uma relação de sugestões de títulos de livros ou uma exposição sobre as obras lidas.

Inicialmente apresentava-se o projeto ao professor e ao estagiário e ainda, indicava-se uma bibliografia básica sobre leitura.

O conjunto de atividades propostas aos alunos 
iniciava-se com uma introdução a respeito dos registros do conhecimento, noções sobre coleções de biblioteca, com ênfase às obras de referência e ainda, orientação para uso da biblioteca do próprio colégio e de seus recursos. Posteriormente, eram realizadas as atividades da leitura propriamente ditas. Entre as atividades desenvolvidas pode-se citar algumas, observando que os títulos ou nomes de cada uma foram atribuídos de acordo com suas características. É importante ressaltar que algumas atividades foram criadas e outras adaptadas da proposta original do projeto.

\subsection{Atividades de Leitura}

. Noçōes sobre História do Livro;

. Noções básicas sobre as partes que compõem o livro;

. Conhecimento do acervo da Biblioteca do Colégio;

Visita à Biblioteca do Colégio;

- Visita às livrarias e editoras da cidade;

- Quantos vagões tem esse trem?

Que termo é esse?

- Reprodução de um conto;

. O Assunto que me interessa ...

. Informação X MCM (Meios de Comunicação de Massa) $X$ Leitura;

- Roteiro para discussão da leitura de um livro;

Quem conta um conto aumenta um ponto; juvenis;

. Exploração de séries e coleçōes de livros infanto-

Fuçando nos jornais;

- Reprodução literária de quadrinhos de humor;

Boletim bibliográfico com sugestōes dos alunos de títulos de livros infanto-juvenis;

- Orientação para elaboração de resenhas e referências bibliográficas;

- Gincana Cultural;

. Dando uma de repórter.

Estas atividades foram desenvolvidas com as $4^{\text {a }}$ séries sendo adequadas ao perfil dos alunos.

A título de ilustração apresenta-se a seguir o roteiro de uma delas.

\section{O ASSUNTO QUE ME INTERESSA}

\subsection{Objetivos:}

- Desenvolver o senso crítico, a criatividade, a expressão oral do aluno;

. Despertar o interesse pela pesquisa em fontes de informação;

- Estimular o aluno no desenvolvimento de um comportamento de busca de informação através de diferentes meios;

\subsection{Roteiro:}

1- Cada aluno ou grupo de alunos deverá escolher um tema de seu interesse;

\section{2 - A atividade constará de:}

\section{Etapa:}

Organização: esta etapa deverá ser realizada em 1 semana de acordo com as datas definidas pela professora, observando os seguintes passos:

a) Definir o assunto que será trabalhado conforme o interesse de cada aluno ou grupo de aluno;

b) Estabelecer que aspectos deverão ser abordados sobre o assunto;

c) Definir a forma de apresentação do "assunto"

Por exemplo: exposição oral com apresentação de cartazes, vídeos, ou audiovisual, ou materiais específicos. Observar que o tempo para apresentação de cada aluno ou grupo de alunos será de 15 minutos.

d) identificar material bibliográfico ou outros que tratem do assunto;

e) listar o material consultado.

\section{$2^{\text {2 Etapa: }}$}

\section{Apresentação do "assunto"}

a) em data a ser estipulada pelo professor, o aluno ou grupo de alunos deverão fazer a apresentação à classe observando o tempo estipulado e a "forma de apresentaçäo";

b) após cada exposição a classe poderá fazer perguntas aos colegas;

c) após a apresentação de todos os "assuntos" deverá ser discutida pela classe o papel da leitura como apoio à pesquisa, de acordo com os seguintes aspectos;

- Estratégia de busca (como procedeu para encontrar as informaçôes: usou material da biblioteca da escola?, da biblioteca pública?, consultou algum amigo, ou professor ou alguém da família? Usou que tipo de material, livros, revistas, figuras, fotografias?);

- Dificuldades para localização da informação;

- Dificuldades encontradas na leitura dos textos selecionados.

Pelo exposto, pode-se considerar que a leitura realmente é importante exige um processo que é complexo pois a formação do leitor implica desde a conscientização do professor em sala de aula e da equipe pedagógica de uma instituição de ensino até a mudança das estratégias de ensino, o que exigiria a existência de infra-estrutura institucional e porque não, governamental.

\section{AVALIAÇÃO}

Conforme mencionado anteriormente as atividades, na medida em que iam sendo desenvolvidas 
eram avaliadas, procurando-se identificar: se os objetivos tinham sido alcançados, o nível de participação dos alunos e o envolvimento do professor com a proposta.

A avaliação obtida no decorrer do período de realização do projeto permitiu que se chegasse às seguintes conclusões:

- Existe a necessidade de uma maior diversificação das atividades de leitura em sala de aula, uma vez que os alunos demonstraram motivação e interesse em participar das atividades propostas;

- O professor é receptivo à proposta de atuar, diversificando suas estratégias de trabalho com a leitura, porém quase sempre não dispõe de tempo e recursos para aplicação de propostas semelhantes por iniciativa própria;

- Os alunos são incentivados a explorar mais a biblioteca para buscar leitura de lazer e de informação;

- As atividades permitem que os alunos descubram a existência de outros suportes de informação que não só o livro, como também jornais, revistas, mapas, slides, fotografias, discos laser e ainda os canais de comunicação de massa, o rádio e a televisão;

- A diversificação das atividades de leitura deveria ser feita com uso da interdisciplinariedade onde professores de diferentes áreas poderiam explorar diferentes conhecimentos;

- A grande maioria dos alunos não possui comportamento de leitura, o que exigiria um trabalho mais constante e de longa duração em que a motivação seria fundamental para que esse comportamento fosse alcançado

- Os professores também deveriam ser mais conscientizados sobre a importância de leitura e a responsabilidade que possuem como intermediadores na formação do leitor;

- A escola como um todo, envolvendo sua equipe pedagógica deveria estar mais consciente a respeito da necessidade de se desenvolver mais seriamente a leitura entre os alunos pela própria aquisição de conhecimento e o desenvolvimento do espírito crítico;

Medidas políticas mais concretas devem ser tomadas principalmente dando-se condições para que os professores se preparem e sejam conscientes da importância da leitura, tenham condições e infraestrura institucional para desenvolver um trabalho sério e concreto com a questão da leitura.

Concluindo, deve-se enfatizar que é inconcebivel ser o processo de leitura ainda deficiente no ensino do $1^{\circ}$ e $2^{\circ}$ graus, ao mesmo tempo em que a humanidade caminha para o terceiro milênio, e a tecnologia tende a se expandir cada vez mais e o conhecimento humano se tornar acessivel, em âmbito maior e com maior velocidade.

Pelo exposto, porém, parece ainda persistir a idéia de que existe conveniência de que os cidadãos continuem sem informação, sem cultura, sem condições de exercer seus direitos. Segundo Silva '....a leitura é um importante instrumento para a libertação do povo brasileiro e para o processo de reconstrução de nossa sociedade. Sendo um mecanismo específico de conscientização, a leitura se constitui numa forma de encontro entre o homem e a realidade sócio-cultural, cujo resultado é um 'situar-se constante frente aos dados dessa realidade..." (1991, p.19-20)

CRUZ, V. A. G. da ; GONDO, T. J. F. Project of Trainning Teachersm of Commnication and Expression in Reading: Report of Experience. Semina: Ci. Sociais/Humanas, Londrina, v. 17, n. 3, p.350-353, Sep. 1996.

ABSTRACT: Report about Trainning Teachers of Communication and Expression from $5^{a}$ to $8^{a}$ series, $1 \%$ level, in reading activits project, realized in 1992 to 1995 period ar "Colégio Estadual Professor José Aloisio de Aragão", Londrina. Introduces in general the developed activities, the methodology used and the evaluation adquired at the end of experimental periods.

KEY-WORDS: Trainning of Teachers; Reading; Reading Activits.

\section{BIBLIOGRAFIA}

BAMBERGER, R. Como incentivar o hábito da teitura. São Paulo: Ática, 1986. 109p.

LAMON, S. P. Extensão Universitária e ensino: análise de uma vivência do prisma de alunos e profissionais de $1^{\circ}$ e $2^{\circ} \mathrm{grau}$ Transinformação, v.6, n.1/2/3, p.124-141, jan./dez. 1984.

MULLER, M. S. et al. Professores de $1^{\circ}$ e $2^{\circ}$ Graus como agentes de integraçāo entre a informaçâo e as atividades de ensino: um diagnóstico das Escolas Públicas de Londrina . Pr. Londrina: UEL, 1988. Relatório de pesquisa apresentado ao $C N P q$ e à $C P G / U E L$.
SILVA, E. T. Leitura na escola e na biblioteca. 3.ed. Campinas: Papiros, 1991, p. 19-20.

SILVA, L. L. M. da A escolarizacão do leitor: a didática da destruição da leitura. Porto Alegre: Mercado Aberto, 1986. $72 p$.

ZILBERMAN, R, org. Leitura em crise na escola, as alternativas do professor. Porto Alegre: Mercado Aberto 1982. $164 \mathrm{p}$ 